\title{
EL PROBLEMA DE LA FUNDAMENTACIÓN FILOSÓFICA DE LOS DERECHOS DE LAS GENERACIONES FUTURAS
}

\author{
Luis Gabriel FERRER ORTEGA* \\ Jesús Guillermo FERRER ORTEGA**
}

\begin{abstract}
RESUMEN: El concepto "derechos de las generaciones futuras", considerado en sí mismo, tiene gran relevancia para las discusiones éticas en torno del medio ambiente y de la investigación genética. No obstante, su fundamento filosófico y su aplicación jurídica se muestran sumamente problemáticas. De ahí la pertinencia de un estudio jurídico-filosófico que, partiendo de la descripción de los instrumentos internacionales y de las legislaciones de los Estados en favor de tales derechos, concluya con una reflexión filosófica sobre conceptos clave como "responsabilidad intergeneracional", "futurología o ciencia de los efectos lejanos del deterioro ambiental" y "ética del género humano". El presente artículo pretende explorar ciertas nociones básicas que sirvan como preámbulo en torno de los derechos de las generaciones futuras.
\end{abstract}

ABSTRACT: The concept "the rights of the future generations" has, by itself, a great relevance for ethical discussions related to the environment and the genetic research. However, their philosophical basis and its legal application are extremely problematic. For that reason, there is a need for a legal-philosophical approach, starting with the description of international instruments and legislations of the States in favor of such rights, concluding with a philosophical reflection on key concepts such as "intergenerational responsibility", "futurology or science of the distant effects of the environmental deterioration" and "ethics of mankind". The present article tries to explore certain essential notions as a basic introduction to the rights of future generations.

RÉSUMÉ: Le concept "droits des générations futures" considère en lui même, possède grand relevance pour les discussions étiques au tour de l'ambiance et l'investigation génétique. Cependant, son fondement philosophique et son application juridique se montrent vraiment problématiques. Pour cet raison la pertinence d'un étudie juridiquephilosophique, qui en partant de la description des instruments internationaux et de las législations des Etats en faveur de ces droits; conclue avec une réflexion philosophique sur les concepts basiques comme "responsabilité intergénérationnel", "futurologie ou science des éloignes effets du détérioration de l'ambiant" et "l'étique du genre humain". Cet article a l'intention d'explorer quelques notions basiques qui sert comme préambule au tour des droits des générations futures.

* Maestro en estudios diplomáticos por el Instituto "Matías Romero" y maestro en derecho por la Universidad de Houston. Miembro del servicio exterior mexicano.

** Maestro en filosofía por la UNAM. 
SUMARIO: I. Introducción. II. Necesidad de un estudio interdisciplinario (jurídico-filosófico) sobre los derechos de las generaciones futuras. III. Instrumentos internacionales. IV. Legislaciones de los Estados. V. Responsabilidad intergeneracional. VI. Conceptos fundamentales de una reflexión $f i-$ losófica sobre los derechos de futuras generaciones. VII. Ausencia de una futurología y de una ética de responsabilidad por el futuro en la discusión sobre los derechos de futuras generaciones.

\section{INTRODUCCIÓN}

En la actualidad asistimos al surgimiento de problemas inquietantes, cuya relevancia no debemos menospreciar y que requieren de soluciones concretas. Debido al auge de la tecnología y de la investigación, la humanidad ha desarrollado una enorme capacidad para transformar su hábitat, capacidad que trasciende el marco temporal en el que vivimos. Todos los cambios que realicemos el día de hoy se extenderán y afectarán, para bien o para mal, a nuestros hijos y a nuestros nietos; podemos afirmar que dichos cambios constituyen una herencia para las futuras generaciones que no alcanzaremos a ver.

Gracias al pensamiento y a la labor de personas ilustres hemos podido tomar conciencia de la repercusión de nuestras acciones presentes en el futuro. El oceanógrafo Jacques Cousteau ha sido un pionero en la reflexión ética y jurídica sobre el legado de las generaciones presentes a las generaciones futuras, prueba de ello es la redacción de su famoso $\mathrm{A}$ Bill of Rights for Future Generations.

Nos proponemos abordar el tema desde distintos ángulos. Nuestra meta consiste en describir el estado actual de la tutela de los derechos y patrimonio de las generaciones venideras, así como en fundamentar la necesidad ética de prevenir graves daños y riesgos a las generaciones que nos sucederán.

Con el fin de exponer la respuesta que ha dado la ciencia jurídica al problema que nos planteamos, examinaremos primeramente los instrumentos internacionales que hacen mención de la materia. La labor realizada por la UNESCO será nuestra principal fuente. Los aportes de esta agencia especializada de la ONU se han materializado en distintos documentos, en los cuales se expresa claramente el imperativo ético de salva- 
guardar los bienes y derechos de nuestros futuros congéneres. En nuestro escrito daremos cuenta de la postura de los Estados ante este fenómeno. Los gobiernos han afrontado dicho fenómeno por medio de legislaciones internas e inclusive, en algunos casos, mediante la creación de instituciones ad hoc.

La lógica interna del problema que nos ocupa conduce a la acuñación de conceptos que no son parte de la tradición de la ciencia jurídica. Nos referimos a conceptos tales como futuras generaciones, responsabilidad y justicia intergeneracional. Además nos veremos forzados al planteamiento de las dificultades que implica la tutela de sujetos no concebidos. Es por ello que nuestro estudio se apoyará en ciertas tesis filosóficas y en una cimentación ética del deber de nuestra generación presente con los futuros pobladores de nuestro planeta.

\section{NECESIDAD DE UN ESTUDIO INTERDISCIPLINARIO (JURÍDICO-FILOSÓFICO) SOBRE LOS DERECHOS DE LAS GENERACIONES FUTURAS}

El tema que hemos elegido presenta grandes dificultades para el especialista en leyes. Apremiado por aporías y por interrogantes que conciernen a cuestiones propiamente éticas y filosóficas, el especialista en leyes se ve conducido a emprender un estudio multidisciplinario. Índice de la necesidad de una investigación interdisciplinaria nos ofrece el concepto de "justicia intergeneracional", noción apenas en ciernes y que ha sido discutida tanto por filósofos como por juristas. El filósofo Vittorio Hoesle, por ejemplo, ha considerado indispensable ampliar la noción de justicia distributiva situándola en tres rubros: justicia social, justicia internacional y justicia intergeneracional. ${ }^{1}$

Presenciamos el incremento de literatura sobre los derechos de las generaciones futuras y su correlativa responsabilidad por parte de la sociedad humana presente. No obstante, se nos impone constatar que en el ámbito académico se respira un cierto escepticismo que es reticente a asignar la titularidad de derechos a una futura comunidad humana (pues obviamente se trata de una comunidad humana aún no nacida o que in-

1 Hoesle, Vittorio, Moral und Politik. Grundlagen einer Politischen Ethik für das 21, J München, Jahrhundert, Beck, 1997, pp. 806 y ss. 
cluso no nacerá, supuesta la contigencia de la continuidad del género humano). Entre los investigadores que se oponen radicalmente a la idea destaca al economista Wilfred Beckerman, quien afirma categóricamente que las generaciones futuras no pueden tener derechos. ${ }^{2}$

Las dificultades no se restrigen a la discusión sobre la existencia de tales derechos y sobre la capacidad del titular (las generaciones futuras) para gozar esos derechos. No menores complicaciones surgen del problema de crear un sistema de justicia que pueda velar por el respeto de estos derechos y que controle la aplicación de sanciones por el incumplimiento de las obligaciones respectivas.

Ahora bien, si se concede, si se acepta la existencia de derechos de las generaciones futuras, se amplía o se debe ampliar la noción de responsabilidad. Tocamos así un punto nodal de toda reflexión jurídica, pues ¿no están en juego aquí los grandes temas del derecho: justicia, derechos (en sentido subjetivo), obligaciones y responsabilidad?

Una de las primeras aproximaciones a nuestro tema fue realizada por la jurista Edith Brown Weiss, quien argumenta que pueden existir obligaciones sin que exista el titular del derecho, ya que las generaciones futuras no son personas determinadas. ${ }^{3}$ Dicha postura nos coloca en una vía de comprensión de los derechos de generaciones futuras que no puede apoyarse en una concepción civilista de los derechos. En efecto, estaríamos hablando de derechos que no pertenecen a los individuos, puesto que son derechos intergeneracionales. Por tanto, de ser aceptable esta teoría, el estudio de nuestro tema no puede seguir los derroteros tradicionales; no podemos equiparar los derechos intergeneraciones a un derecho real o personal, como es el caso del derecho a la propiedad sobre una cosa o una deuda a un banco.

2 Beckerman, Wilfred, Our Obligations to Future Generations, Nueva York, The Columbia Earth Institute, Columbia University, EARTHmatters, invierno de 1999-2000, http://www.earthinstitute.columbia.edu/library/earthmatters/spring2000/pages/page18. html.

3 Brown Weiss, Edith, "Intergenerational Fairness and Rights of Future Generations", Generational Justice, Stiftung für die Rechte zukünftiger Generationen, núm. 3, noviembre de 2002, pp. 1 y 5. 


\section{INSTRUMENTOS INTERNACIONALES}

La preocupación por nuestras obligaciones con las generaciones futuras surge preponderantemente de las discusiones respecto de la relación del hombre con el medio ambiente. Prueba de ello es que los documentos internacionales donde existe una mayor referencia a las obligaciones con las generaciones futuras provienen de tratados y resoluciones que giran en torno al derecho ambiental. La problemática del medio ambiente no es, sin embargo, la única fuente creadora de normas.

La Declaración de la Conferencia de las Naciones Unidas sobre el Medio Humano, resultado de la reunión en Estocolmo del 5 al 16 de junio de 1972 (Declaración de Estocolmo), conviene que "la defensa y el mejoramiento del medio humano para las generaciones presentes y futuras se ha convertido en meta imperiosa de la humanidad". En la Declaración de Estocolmo se establece claramente como un principio que: "El hombre tiene derecho fundamental a la libertad, la igualdad y el disfrute de condiciones de vida adecuadas en un medio de calidad tal que le permita llevar una vida digna y gozar de bienestar, y tiene la solemne obligación de proteger y mejorar el medio para las generaciones presentes y futuras". ${ }^{4}$ Asimismo se establece como principio que los recursos naturales deben preservarse en beneficio de las generaciones presentes y futuras.

No queremos dejar de mencionar el Proyecto de Carta de Derechos Humanos Emergentes que tutela el derecho a habitar el planeta y el medio ambiente, y a su vez, resalta el deber de defender el sustento y continuidad de su entorno para las futuras generaciones. Igual señalamiento hace dicho instrumento al referirse al derecho a la democracia solidaria.

Un instrumento internacional fundamental es la Declaración sobre las Responsabilidades de las Generaciones Actuales para con las Generaciones Futuras, adoptada el 12 de noviembre de 1997 por la Conferencia General de la UNESCO. No queremos omitir la importancia que tuvo la reunión de expertos de la UNESCO y el equipo Cousteau en la La Laguna (Tenerife, Canarias), que culminó en la Declaración Universal de los Derechos Humanos de las Generaciones Futuras.

En la declaración de 1997 se enlista un catálogo de obligaciones de las generaciones actuales para salvaguardar los intereses y necesidades

4 Principio 1, las cursivas son mías. 
de las generaciones presentes y futuras. Entre estas obligaciones de las generaciones presentes se cuentan:

Libertad de elección: Garantizar que las generaciones futuras puedan escoger libremente su sistema político, económico y social y preservar su diversidad cultural y religiosa (artículo 2o.)

Mantenimiento y perpetuación de la humanidad: Asegurar el mantenimiento y la perpetuación de la humanidad, respetando debidamente la dignidad de la persona humana (artículo 3o.)

Preservación de la vida en la Tierra: Legar a las generaciones futuras un planeta que en un futuro no esté irreversiblemente dañado por la actividad del ser humano, procurando utilizar los recursos naturales razonablemente y atender a que no se comprometa la vida con modificaciones nocivas de los ecosistemas y a que el progreso científico y técnico en todos los ámbitos no cause perjuicios a la vida en la Tierra (artículo 4o.)

Protección del medio ambiente: Procurar un desarrollo sostenible y preservar las condiciones de la vida $\mathrm{y}$, especialmente, la calidad e integridad del medio ambiente (artículo 5o.). En cuanto a la preservación del equilibrio ecológico existen diversos instrumentos internacionales que obligan a la protección del medio humano para las futuras generaciones. La Convención Marco de las Naciones Unidas sobre el Cambio Climáti$\mathrm{co}^{5}$ enuncia que los Estados tienen que proteger el sistema climático en beneficio de las generaciones presentes y futuras, sobre la base de la equidad y de conformidad con sus responsabilidades comunes pero diferenciadas y sus respectivas capacidades (artículo 3o., fracción primera). En el preámbulo del Convenio sobre la Diversidad Biológica de 1992 se manifiesta que las partes acordaron la convención, entre otras razones "resueltas a conservar y utilizar de manera sostenible la diversidad biológica en beneficio de las generaciones actuales y futuras". La Corte Internacional de Justicia ha manifestado su preocupación por el daño que puede causar el uso de las armas nucleares para las futuras generaciones. En la Opinión sobre la Legalidad de La Amenaza o el uso de Armas Nucleares, el tribunal internacional expresó que el uso de de las armas nucleares sería un peligro serio para las generaciones futuras. La radiación ionizante tiene el potencial de causar daño al ambiente, alimentos y eco-

5 Firmada en Nueva York el 9 de mayo de 1992. 
sistema marino futuros, así como causar defectos y enfermedades a las generaciones futuras. ${ }^{6}$

Genoma humano: Proteger el genoma humano, respetándose plenamente la dignidad de la persona humana y los derechos humanos (artículo 6o.). La misma Declaración Universal sobre Bioética y Derechos Humanos del 2005 señala en su artículo 14 que "se deberían tener debidamente en cuenta las repercusiones de las ciencias de la vida en las generaciones futuras, en particular en su constitución genética". ${ }^{7}$

Diversidad biológica: preservar la diversidad biológica. El progreso científico y tecnológico no debe perjudicar ni comprometer de ningún modo la preservación de la especie humana ni de otras especies (artículo 6o.).

Diversidad cultural: Preservar la diversidad cultural de la humanidad respetando debidamente los derechos humanos y libertades fundamentales (artículo 7o.). En el seno de la UNESCO en París se suscribió la Convención sobre la Protección y la Promoción de la Diversidad de las Expresiones Culturales en 2005. ${ }^{8}$ Dentro de los principios rectores de dicha Convención se reconoce el principio de desarrollo sostenible que admite la conservación de la riqueza cultural como una condición esencial en beneficio de las generaciones futuras.

Patrimonio cultural: Identificar, proteger y conservar el patrimonio cultural material e inmaterial y transmitir ese patrimonio común a las generaciones futuras (artículo 7o.). Desde 1972 se cristalizó esta protección en la Convención para la Protección del Patrimonio Mundial, Cultural y Natural. En dicho instrumento, y desde esa fecha, ya se reconoce la obligación de los Estados para las generaciones futuras (artículo 4o.). En el 2003 se concluyó la Convención para la Salvaguardia del Patrimonio Cultural Inmaterial. Aún más específico, en 2001 se finalizó la Convención sobre la Protección del Patrimonio Cultural Subacuático.

6 Legality of the Threat or Use of Nuclear Weapons. Advisory Opinion del 8 de Julio de 1996, International Court of Justice, parágrafos 35 y 36, http://www.icj-cij.org/ docket/files/95/7495.pdf.

7 Gros Espiell, Héctor, "Las recomendaciones de la UNESCO en materia de bioética, genética y futuras generaciones. Su importancia y su incidencia en el desarrollo del derecho internacional", Anuario de Derecho Constitucional Latinoamericano, Uruguay, año 12, t. 2, 2006, pp. 1405-1416.

8 Nuestro país la ratificó el 5 de julio de 2006. La Unión Europea se adhirió a este instrumento en bloque. Estados Unidos se ha mantenido al margen. 
Es muy destacable la labor de la UNESCO en las tareas de identificación y preservación del patrimonio cultural de la humanidad. La labor de esta agencia especializada de la ONU no sólo se limita a la elaboración de la lista de sitios merecedores de considerarse en esta categoría, de igual manera involucra esfuerzos de preservación, restauración y rehabilitación en casos de daños. Entre los ejemplos que podríamos citar de los trabajos que lleva a cabo la UNESCO se destacan las tareas de restauración y rehabilitación de sitios afectados en Kosovo, la firma de un Memorando de Entendimiento con Irak para la reconstrucción de la Mezquita de Al-Askari en Samarra, ${ }^{9}$ la tarea conjunta con el gobierno japonés para la preservación del Templo Abu Simbel en Nubia, el Temple de Borobudur en Indonesia y el sitio arqueológico de Moenjodaro en Pakistán, sólo por citar algunos. De igual manera, la preservación del patrimonio cultural inmaterial ha tenido un gran empuje en los últimos años. ${ }^{10}$

Patrimonio común de la humanidad: Utilizar el patrimonio común de la humanidad, según lo define el derecho internacional, sin comprometerlo de modo irreversible (artículo 8o.).

Paz: Velar por que tanto éstas como las generaciones futuras aprendan a convivir en un ambiente de paz, seguridad y respeto del derecho internacional, los derechos humanos y las libertades fundamentales (artículo 9o.). El mismo preámbulo de la Carta de Naciones Unidas, firmada el 26 de junio de 1945 en San Francisco, señala "Nosotros los pueblos de las Naciones Unidas resueltos a preservar a las generaciones venideras $^{11}$ del flagelo de la guerra que dos veces durante nuestra vida ha infligido a la humanidad sufrimientos indecibles".

Desarrollo: Legar a las futuras generaciones las condiciones para un desarrollo socioeconómico equitativo, sostenible y universal, tanto individual como colectivo, en particular, mediante una utilización justa y

9 UNESCO, Press Release No. 2007-75/, UNESCOPRESS, 26 de junio de 2007.

10 UNESCO, Internacional Conference: Globalization and Intangible Cultural Heritage Report, París, UNESCO, 2005. Esta obra presenta los resultados de la Conferencia Internacional sobre Globalización y el Patrimonio Cultural Inmaterial que se llevó a cabo en la sede de la UNESCO del 26 al 27 de agosto de 2004, y en ella se compilan una serie de artículos de expertos en la que se expone la contribución y los riesgos de la globalización al patrimonio cultural inmaterial. De igual manera, en dicha conferencia se reconoce la responsabilidad universal de proteger y transmitir los valores y tradiciones de todas las culturas para las futuras generaciones.

11 Las cursivas son mías. 
prudente de los recursos disponibles a fin de luchar contra la pobreza (artículo 10o.).

Educación: Se reconoce como un instrumento importante para el desarrollo de los seres humanos y las sociedades. Igualmente, se instruye que deberá utilizarse para fomentar la paz, la justicia, el entendimiento, la tolerancia y la igualdad en beneficio de las generaciones actuales y futuras (artículo 10o.).

No discriminación: Abstenerse de realizar actividades y de tomar medidas que puedan ocasionar o perpetuar cualquier forma de discriminación para las generaciones futuras (artículo 11o.).

Sin duda, bajo el auspicio de la UNESCO se ha fortalecido la teoría de la responsabilidad para las generaciones venideras, y es posible encontrar distintas declaraciones emanadas de dicha organización en las que se ratifica dicho principio. Más allá de la creación de instrumentos internacionales, la UNESCO ha procurado tener una actuación activa encaminada a la protección.

\section{LEGISLACIONES DE LOS ESTADOS}

La mención de las generaciones futuras en las legislaciones de algunos Estados ha alcanzado, en algunos casos, un rango constitucional. Algunos países han adoptado medidas dentro de la legislación federal, y en el caso de otros países se han creado incluso instituciones representativas de los intereses de las generaciones futuras.

La mención de las legislaciones de los países que enlistamos no es exhaustiva y pretende solamente representar la incorporación de la responsabilidad hacia las futuras generaciones en el orden interno.

\section{Alemania}

En el caso particular de Alemania, la Constitución toma en consideración su responsabilidad para las generaciones futuras. El artículo 20.a. previene que el Estado, teniendo en cuenta el compromiso con las generaciones futuras, protegerá las bases naturales de la vida. Esta adenda constitucional fue introducida en 2002. ${ }^{12}$

12 "Der Staat schützt auch in Verantwortung für die künftigen Generationen die natürlichen Lebensgrundlagen und die Tiere im Rahmen der verfassungsmäßigen Ordnung durch 


\section{Polonia}

Polonia establece en su ley fundamental la responsabilidad del Estado por las futuras generaciones. Desde el preámbulo de su Constitución, el Estado polaco observa que el pueblo de Polonia está obligado a legar a las futuras generaciones todo valor de su herencia milenaria.

Concretamente instruye a las autoridades a adoptar políticas que aseguren la certeza ecológica de las futuras generaciones (sección primera del artículo 74).

\section{Israel}

En Israel se ha institucionalizado la Comisión para las Futuras Generaciones, órgano del Parlamento israelí. Tiene su fundamento en la Knesset, legislación que regula al Parlamento. El objetivo primordial de esta Comisión es vigilar que las iniciativas que se introducen a discusión no tengan un efecto negativo en las generaciones futuras. Dicha comisión posee facultad de iniciativa. ${ }^{13}$

\section{Finlandia}

Desde 1999, Finlandia cuenta en su Parlamento con un Comité para el Futuro, el cual realiza investigaciones e interactúa en distintos temas con los comités del mismo Congreso finlandés. Entre las tareas del Comité se cuenta mantener un diálogo constante con la oficina del primer ministro y realizar estudios de impacto sobre la innovación de tecnología. ${ }^{14}$

die Gesetzgebung und nach Maßgabe von Gesetz und Recht durch die vollziehende Gewalt und die Rechtsprechung. Podemos traducir así el pasaje citado: "Consciente también de su responsabilidad hacia futuras generaciones, el Estado protege las bases de la vida y los animales, dentro del marco del orden constitucional via legislativa, y de acuerdo con la ley y la justicia, por el Poder Ejecutivo y Judicial".

13 Shoham, Shlomo y Lamay, Nira, "Commission for Future Generations in the Knesset - Lessons Learnt”, Generational Justice, Stiftung für die Rechte Zukünftiger Generationen, núm. 3, noviembre de 2002, p. 35.

14 Tiihonen, Paula, "The Committee for the Future - Future policy", Generational Justice, Stiftung für die Rechte Zukünftiger Generationen, núm. 3, noviembre de 2002, pp. 36 y 37. 


\section{México}

En algunos Estados se hace mención a las generaciones futuras dentro de los principios rectores del derecho ambiental interno.

La fracción V del artículo 15 de la Ley General del Equilibrio Ecológico y la Protección al Ambiente de 1988 señala que para la formulación y conducción de la política ambiental y la expedición de normas, el Ejecutivo Federal observará como principio que: "La responsabilidad respecto al equilibrio ecológico, comprende tanto las condiciones presentes como las que determinarán la calidad de la vida de las futuras generaciones".

De acuerdo al artículo tercero se define:

Desarrollo sustentable: El proceso evaluable mediante criterios e indicadores del carácter ambiental, económico y social que tiende a mejorar la calidad de vida y la productividad de las personas, que se funda en medidas apropiadas de preservación del equilibrio ecológico, protección del ambiente y aprovechamiento de recursos naturales, de manera que no se comprometa la satisfacción de las necesidades de las generaciones futuras. ${ }^{15}$

\section{Bélgica}

La Ley relativa a la Protección del Medio de los Espacios Marinos de Bélgica, dispone en la sección 4a. de su artículo cuarto que la aplicación del principio del desarrollo sostenible implica que la utilización de recursos naturales será en una medida tal que permita la disponibilidad suficiente de ellos para futuras generaciones. ${ }^{16}$

15 El énfasis es nuestro. Ley publicada en el Diario Oficial de la Federación del 28 de enero de 1988. Versión en línea actualizada en http://www.diputados.gob.mx/LeyesBi blio/index.htm.

16 El énfasis es nuestro. Literalmente: “§ 4. L’application du principe de gestion durable dans les espaces marins implique que les ressources naturelles sont tenues dans une mesure suffisante à la disposition des générations futures et que les effets des interventions de l'homme ne dépassent pas les capacités d'absorption de l'environnement des espaces marins. A cette fin, les écosystèmes et les processus écologiques nécessaires pour le bon fonctionnement du milieu marin seront protégés, la diversité biologique sera préservée et la conservation de la nature sera stimulée". 


\section{Estados Unidos}

La National Environmental Policy Act de 1969 señala que es la intención del Gobierno Federal utilizar todos los medios para crear y mantener las condiciones en las que el hombre y la naturaleza puedan existir en una armonía productiva, y satisfacer los requerimientos sociales, económicos o de cualquier otra naturaleza de las generaciones presentes y futuras de sus gobernados. ${ }^{17}$ Sin embargo, la mención a las generaciones futuras en la legislación estadounidense es amplia y puede hallarse en leyes relativas a áreas naturales, desarrollo de fuentes energéticas, documentos históricos, bienes nacionales, etcétera.

\section{Unión Europea}

A pesar de no estar en vigor, la pretendida Constitución Europea menciona en su preámbulo: "SEgUROS de que, 'Unida en la diversidad', Europa les brinda las mejores posibilidades de proseguir, respetando los derechos de todos y conscientes de su responsabilidad para con las generaciones futuras y la Tierra, la gran aventura que hace de ella un espacio privilegiado para la esperanza humana".

Como se puede observar, los Estados han tenido una distinta reacción ante el fenómeno de la responsabilidad hacia las futuras generaciones. La fórmula para crear una tutela no es homogénea y puede llevarse hasta la Ley Fundamental como es el caso de Alemania ${ }^{18}$ o por métodos más comunes, como en otros países en los que se incorpora a sus leyes inferiores. Resulta interesante el caso de Israel con la creación de una

1742 USC § 4331. Literalmente: “(a) The Congress... declares that it is the continuing policy of the Federal Government, in cooperation with State and local governments, and other concerned public and private organizations, to use all practicable means and measures, including financial and technical assistance, in a manner calculated to foster and promote the general welfare, to create and maintain conditions under which man and nature can exist in productive harmony, and fulfill the social, economic, and other requirements of present and future generations of Americans".

18 Tremmel, Jörg, "Establishing the Rights of Future Generations in National Constitutions", Generational Justice, Stiftung für die Rechte Zukünftiger Generationen, núm. 3 , noviembre de 2002, pp. 29-30. Este autor propone como alternativas la adopción de la tutela a los derechos de las futuras generaciones en la ley suprema de cada Estado con la consecuente custodia de las cortes constitucionales o la creación de instituciones ad hoc tipo defensor de los derechos humanos, consejos o comités de las futuras generaciones, dependiendo de la manera en que sea más fácil su recepción en cada país. 
Comisión para las Futuras Generaciones, que institucionaliza, de cierta manera la protección de estos derechos.

\section{RESPONSABILIDAD INTERGENERACIONAL}

Una vez que hemos considerado algunos instrumentos internacionales y las legislaciones internas que enuncian la responsabilidad hacia las generaciones futuras, surge la necesidad de discutir y valorar si dicha responsabilidad es una norma jurídica, una directriz política o pertenece al campo de la ética, sin que medie obligación jurídica o política.

Nuestro punto de partida es la siguiente constatación: Los Estados pueden crear derechos y obligaciones conforme al principio de pacta sunt servanda. Al evidenciarse que la responsabilidad hacia las generaciones futuras se repite en diversos tratados internacionales, se estaría en condiciones de afirmar que los Estados-parte han decidido observar una conducta de respeto hacia un sujeto (las futuras generaciones) que no es tangible en nuestro espacio temporal.

Baste mencionar que la Convención sobre la Protección del Patrimonio Mundial, Cultural y Natural habla de la obligación de identificar, proteger, conservar, rehabilitar y transmitir a las generaciones futuras el patrimonio cultural y natural situado en su territorio.

A lo largo de su evolución, el derecho ha creado ficciones jurídicas en las cuales se ponen en juego sujetos de derechos intangibles. Tal es el caso de las sociedades y asociaciones que pueden tener nombre, patrimonio, derechos y obligaciones, y una representación. De igual manera, el Estado, ente impalpable, puede tener actividad jurídica, tanto con particulares como con otros Estados, organizaciones internacionales y tribunales. Por consiguiente carece de contundencia, incluso es irrelevante para la cuestión que nos ocupa, el argumento de que las futuras generaciones son "intangibles".

La ciencia jurídica puede además concebir que los derechos y obligaciones persistan a través del tiempo. Un tratado que delimite la frontera entre países colindantes sólo subsistirá otorgando derechos y obligaciones para sus gobiernos y pobladores, generación tras generación. La prohibición de la esclavitud concierne a las generaciones actuales y futuras, y tuvo vigencia para la sociedad que así lo determinó. 
Es necesario concluir, por tanto, que la "herencia" legal de nuestros antepasados se convierte en un catálogo de derechos vigentes día con día y que trasciende el marco temporal presente.

No cabe afirmar que, en vista de una teoría de la responsabilidad intergeneracional, la sociedad actual podría hacer un reclamo legal a las anteriores por la pérdida de bienes o recursos pasados. Es absurdo pensar que puede reclamarse a los godos por la destrucción del templo de Artemisa en Efeso, o a los marinos portugueses y holandeses por la extinción del pájaro dodó. Sin embargo, como se discutirá en el último apartado de este trabajo, la conciencia histórica, la reminiscencia de la irresponsabilidad de los actos pasados emerge en el daño presente, más aun si éste es irreparable. De igual manera nuestros aciertos y faltas trascenderán a nuestros descendientes.

Puesto que no estamos en condiciones de confrontar a las generaciones pasadas con el alcance de sus acciones en el presente, debemos partir de la siguiente constatación: toda teoría sobre la justicia intergeneracional es contemporánea y corresponde a la evolución del pensamiento actual, al desprendimiento del egoísmo de los habitantes presentes. La revisión de la historia, sin duda, nos ayuda a que despierte la conciencia de nuestro deber con los futuros pobladores del planeta.

Los actos del pasado pueden ser ensalzados o reprochables. Tal es la lección que nos ofrece la historia. Ahora bien, podemos plantear exigencias a la conducta de nuestra generación, siempre y cuando se funden las instituciones que vigilen los intereses de las generaciones futuras.

Edith Brown Weiss ${ }^{19}$ propone tres principios básicos de justicia intergeneracional:

- Cada generación deberá conservar la diversidad de la base de sus recursos naturales y culturales, con el fin de no coartar indebidamente las opciones de las generaciones futuras para solucionar sus problemas y satisfacer sus propios valores. Igualmente tendrá derecho de gozar una diversidad comparable a la que disfrutó la generación previa.

19 Brown Weiss, Edith, Environmental Change and International Law: New Challenges and Dimensions, Tokyo, United Nations University Press, 1992. El desarrollo de estos principios puede encontrarse en el capítulo 12. 
- Cada generación deberá mantener la calidad de la tierra para que pueda ser entregada en una condición que no sea inferior de lo que la recibió.

- Cada generación deberá otorgar a sus miembros derechos equitativos para que puedan acceder al legado de la generación anterior y deberá conservar este acceso para las generaciones posteriores.

\section{CONCEPTOS FUNDAMENTALES DE UNA REFLEXIÓN FILOSÓFICA SOBRE LOS DERECHOS DE FUTURAS GENERACIONES}

El concepto de responsabilidad intergeneracional debe estar en el centro de cualquier tentativa de fundamentación de los derechos de generaciones futuras. Ahora bien, el análisis de este concepto nos revela una serie de cuestiones que atañen a la reflexión propiamente filosófica. Una de estas cuestiones concierne a nuestra capacidad para prever el futuro, otra concierne a la actitud ética que debemos asumir con base en nuestras previsiones. Una vez que estas cuestiones han sido resueltas, se está en condiciones de hablar de una extensión de la responsabilidad más allá del mero presente.

No pretendemos agotar el tema del fundamento filosófico de la responsabilidad intergeneracional. Nuestra tarea es más modesta: Queremos indicar las líneas de argumentación que pueden conducir a una justificación filosófica del concepto de responsabilidad intergeneracional, el cual, como vimos, desempeña un papel decisivo para la legislación respecto de derechos de las generaciones futuras. El tratamiento detallado de cada una de estas líneas de argumentación filosófica exige investigaciones ulteriores y deseables. He aquí los temas filosóficos que, desde nuestro punto de vista, constituyen la base de cualquier indagación jurídica sobre los conceptos de responsabilidad y justicia intergeneracionales.

\section{Posibilidad de una "futurología" y una "ciencia de los efectos}

lejanos de la acción técnica" como fundamento de la responsabilidad por futuras generaciones

El filósofo alemán Dieter Birnbacher ha expuesto las características de una "futurología" que se orienta sobre todo a la resolución de problemas prácticos: la institucionalización de la paz, la desaparición del hambre y de la miseria, el vencimiento de la explotación y el sometimiento, 
la democratización del Estado y de la sociedad, y desde luego la explotación de los recursos naturales. La futurología no pretende ni puede pretender el estatuto de "ciencia" (Wissenschaft), sino de un arte (Kunst), en concreto de un arte de la previsión.

La filosofía, especialmente en cuanto "razón práctica", contribuye al desarrollo de la futurología aplicada a cuestiones de índole ética. Así formula Birnbacher la interrogante propiamente ética de la futurología, interrogante que abarca el problema del medio ambiente: “¿En qué medida el individuo debe sentirse responsable de su propio futuro, del futuro de su familia, de su nación, de su género? ¿Hasta qué punto se puede exigir al individuo solidarizarse activamente con una futura humanidad, cuyas necesidades, valores y formas de vida son desconocidas, y que incluso pueden diferir de las nuestras?". ${ }^{20}$

La necesidad moral de que practiquemos una "ascética ecológica" (ökologische Askese), esto es, un uso racional de los recursos naturales, se basa no sólo en una responsabilidad por la humanidad contemporánea, sino por las generaciones futuras.

Hans Jonas habla por su parte de un saber científico (wissenschaftliches Wissen) concerniente a futuras situaciones del hombre y del mundo que deben ser valoradas y juzgadas desde un punto de vista ético. ${ }^{21}$ Desde luego tales situaciones son pensadas a partir de las consecuencias que, a mediano y largo plazo, se siguen de la presente actividad técnica. La consideración ética de previsibles estados del hombre y del mundo es guiada ciertamente por principios ideales, pero también por la urgencia de una aplicación política, la cual nunca puede prescindir de hipótesis sobre lo que cabe esperar como consecuencia de tal o cual decisión política. Justamente estas hipótesis fundadas determinan, para la aplicación política, lo que debe exigirse o debe evitarse.

20 "Inwieweit soll sich der Einzelne für die Zukunft — seine eigene Zukunft, die Zukunft seiner Familie, seiner Nation, seiner Gattung — verantwortlich fühlen? In welchem Umfange ist es ihm überhaupt zuzumuten, sich handelnd mit einer zukünftigen Menschheit zu solidarisieren, deren Bedürfnisse, Wertvorstellungen und Lebensformen gänzlich unbekannt sind und unseren gerandezu entgegengesetzt sein mögen?". Birnbacher, Dieter, "Futurologie -Rückblick und Ausblick", Philosophische Rundschau, núm. 27, 1980, p. 274.

21 Cfr. Jonas, Hans, Das Prinzip Verantwortung. Versuch einer Ethik für die technologische Zivilization, Frankfurt am Main, Suhrkamp Verlag, 2003. 


\section{2. "Heurística del temor"}

Se trata de un concepto introducido por Hans Jonas. Si el uso del poder tecnológico debe ser normado éticamente, se impone una anticipación de los peligros que dicho poder pueda acarrear en el futuro. Mediante una "heurística del temor" (Heuristik der Furcht), cuyo hilo conductor es la representación de las consecuencias posibles del abuso del poder tecnológico (anticipaciones que la futurología controla científicamente), pretende Hans Jonas obtener las normas éticas que regulen la aplicación de la tecnología tanto a los seres humanos como a la naturaleza. ${ }^{22}$

Ahora bien, a nosotros nos interesa resaltar el siguiente aspecto de las reflexiones de Hans Jonas: en la medida en que una ética para el poder tecnológico vislumbra un escenario de riesgos en el futuro de la humanidad, ella trasciende el ámbito de las comunidades estrictamente contemporáneas. Surge entonces la interrogante sobre nuestro deber hacia futuras generaciones de seres humanos. Se trata, para Hans Jonas, de la interrogante sobre nuestra responsabilidad ante la existencia y seguridad de futuras generaciones de seres humanos, responsabilidad cuyo necesario correlato son derechos de tales futuras generaciones de seres humanos (Hans Jonas tematiza no tanto los derechos de futuras generaciones, sino los deberes de las generaciones presentes con las futuras).

22 La propuesta de Hans Jonas conlleva un distanciamiento de las "éticas tradicionales". Éstas, según la opinión de Hans Jonas, carecen del bagaje conceptual necesario para valorar y normar las modalidades del poder tecnológico. Una ética ajustada a los fenómenos de la aplicación de la técnica a la naturaleza requiere de criterios nuevos. Hans Jonas escribe "Was kann als Kompaß dienen? Die vorausgedachte Gefahr selber! In ihrem Wetterleuchten aus der Zukunft, im Vorschein ihres planetarischen Umfanges und ihres humanen Tiefganges, werden allererst die etischen Prinzipien entdeckbar, aus denen sich die neuen Pflichten neuer Macht herleiten lassen. Dies nenne ich die, Heuristik der Furcht': Erst die vorausgesehene Verzerrung des Menschen verhilft uns zu dem davor zu bewahrenden Begriff des Menschen. Wir wissen erst, was auf dem Spiele steht, wenn wir wissen, daß es auf dem Spiele steht”. “¿Qué puede servir como compás? ¡La previsión del peligro mismo! Los principios éticos, a partir de los cuales se deducen los deberes del nuevo poder, se descubrirán en su relampagueo desde el futuro, en la manifestación de su dimensión planetaria y su hondura humana. A esto llamo "heurística del temor"; solamente la anticipación de la desfiguración del hombre nos ayuda a obtener un concepto del hombre que nos proteja de tal desfiguración. Sólo sabemos lo que está en juego, cuando sabemos que está en juego". Ibidem, pp. 7 y 8. 


\section{3. "Ética del género humano"}

Si bien Jürgen Habermas no aborda directamente el tema de la responsabilidad por generaciones futuras en relación con el medio ambiente, él se vale, sin embargo, de métodos y conceptos que justifican una extensión de la responsabilidad, y por consiguiente de los derechos, hacia el futuro. En uno de sus últimos escritos, Die Zukunft der menschlichen Natur. Auf dem Weg zu einer liberalen Eugenik?, Habermas confronta, desde un punto de vista ético, la investigación y la técnica genéticas. Nos interesa subrayar que Habermas no parte de una discusión del estatuto moral de la vida humana pre-personal (vorpersonal), sino de la perspectiva de un futuro posible, en el cual imperaría una eugenesia regulada por la oferta y la demanda. En última instancia, intenta Habermas dirigir la atención del lector hacia un "denso tejido intergeneracional de acciones" (Ein dichter intergenerationeller Handlungsstrang), del cual nadie se siente llamado a rendir cuentas, "porque más bien uno se abre paso, de manera unilateral y en dirección vertical, a través de las redes de interacción contemporáneas". ${ }^{23}$ La ética del género (Ethik der Gattung) se construye desde el punto de vista del futuro de la naturaleza humana, futuro que es anticipable a partir de la consideración del mencionado "tejido intergeneracional de acciones".

En Habermas observamos un esfuerzo por extender el concepto de responsabilidad más allá de las "redes de interacción contemporáneas", hasta tocar el "denso tejido intergeneracional de acciones" que afectaran a generaciones futuras. De este "denso tejido intergeneracional de acciones" y sus previsibles consecuencias, podemos decir, no se sienten llamados a rendir cuentas quienes destruyen el medio ambiente sin que una legislación les ponga barreras.

\section{4. "Justicia entre generaciones"}

Axel Gosserie, autor del libro Penser la justice entre les générations: De l'affaire Perruche à la réforme des retraites, ${ }^{24}$ ha examinado desde

23 "Weil er einseitig in vertikaler Richtung durch die zeitgenösischen Interaktionsnetze hindurchgreift". Habermas, Jürgen, Die Zukunft der menschlichen Natur. Auf dem Weg zu einer liberalen Eugenik?, Frankfurt am Main, Suhrkamp Verlag, 2005, p. 10.

24 Gosserie, Axel, Penser la justice entre les générations: De l'affaire Perruche à la réforme des retraites, París, Aubier, 2004. 
un punto de vista filosófico las objeciones dirigidas al concepto de responsabilidad por las generaciones futuras: la primera objeción aduce que carece de sentido conferir derechos a personas que no existen aún; Gosserie argumenta que esta objeción, si bien es pertinente, no es concluyente, pues por una parte es probable que haya personas en el futuro, y por otra parte es plausible afirmar que ciertas de nuestras acciones presentes podrían afectar a tales personas. No hay por consiguiente, prosigue Gosserie, un impedimento absoluto para considerarnos titulares de obligaciones ya no con derechos actuales de personas actuales, sino con derechos que entrarán en vigor cuando otras personas comiencen a existir.

Gosserie defiende así la idea de obligaciones actuales concernientes a derechos futuros. No se trata de una idea salida de la nada o que no sea de alguna manera visible en las actividades humanas. Gosserie pone el ejemplo de un productor de alimentos para bebés. El productor asume o debe asumir una responsabilidad por sujetos que están por nacer o no han nacido aún.

La segunda objeción parte de la no-identidad de la persona a quien en un futuro podría afectarse. Sin embargo, el hecho de que haya obligaciones directas con una persona futura, aún no identificable, no nos exime de obligaciones con el futuro.

Estas obligaciones, según Gosserie, se fundamentan en el hecho de que, desde el nacimiento, somos "deudores". Hemos recibido, desde el nacimiento, un bagaje científico, tecnológico, cultural y material que debemos restituir, al menos en la misma medida en que nos fue transmitido, a las generaciones siguientes. La responsabilidad por generaciones futuras se cimenta en la idea de una "reciprocidad indirecta". No estamos en condiciones de pagar la deuda con la generación precedente, por lo cual debemos "devolver" lo recibido a la generación siguiente.

Con base en las consideraciones anteriores podemos concluir lo siguiente: la fundamentación de derechos de futuras generaciones exige una reflexión filosófica que se mueva en dos ámbitos, uno propiamente epistemológico y otro propiamente ético, ambos desde luego vinculados entre sí. Por una parte se impone la necesidad de discurrir sobre el estatuto científico de una futurología, ciencia del futuro, que haga pronósticos fundados en la experiencia, y por otra parte hace falta una ética que vaya más allá de la esfera del presente y valore las situaciones que la futurología describe. 
Uno de los rasgos característicos de esta ética consiste en la extensión del concepto de responsabilidad. Ésta ha sido limitada con frecuencia al dominio de hechos actuales, patentes, constatables, sin que haya de por medio una anticipación de los efectos que las acciones del presente puedan causar en el futuro. La cuestión que nos proponemos resolver es saber si, mediante tal limitación, no se destruye el sentido mismo del concepto de responsabilidad. Otra característica de la ética que atiende la responsabilidad por futuras generaciones, como se advierte en las meditaciones de Axel Gosserie, enfatiza el deber de reconocimiento a las generaciones anteriores, reconocimiento que sólo puede concretarse actuando en favor de generaciones futuras. Esto equivale a decir que la ética como ciencia puramente ideal, sin atención a la situación histórica, a la "conciencia histórica" en diálogo con la tradición, usando términos de la filosofía hermenéutica de H. G. Gadamer, no es capaz de fundamentar la responsabilidad por generaciones futuras.

La pregunta que ahora nos planteamos puede ser formulada de la siguiente manera: en la polémica sobre los derechos de futuras generaciones, más aún, en la situación legislativa actual que ignora esos derechos, ¿no se extrañan los aportes de la futurología y de la ética que, centrada en la extensión de la responsabilidad y en el concepto de "gratitud histórica" valora los posibles hechos que aquélla describe?

\section{AUSENCIA DE UNA FUTUROLOGÍA Y DE UNA ÉTICA DE RESPONSABILIDAD POR EL FUTURO EN LA DISCUSIÓN SOBRE LOS DERECHOS DE FUTURAS GENERACIONES}

Por último dejamos abiertas una serie de preguntas que nos deben invitar a tomar conciencia sobre la importancia de nuestro tema y sobre la necesidad de una tarea interdisciplinaria, por medio de la cual la filosofía y la ciencia jurídica pueden contribuir a resolver cuestiones de la mayor relevancia ética para nosotros y para las generaciones por venir.

1) En la polémica respecto de los derechos de generaciones futuras, e incluso en las legislaciones vigentes que no se ocupan de los derechos de generaciones futuras, ¿no presuponen un concepto restringido de los "hechos" sobre los cuales es preciso legislar, es decir, al restringirse a las "redes de interacción contemporáneas" (Habermas) no prejuzgan la posibilidad de una "futurología" que anticipe hechos con validez científica? (Anticipación que no es determinista ni puede serlo; su "cientificidad" en 
relación con la ética y el derecho radica justamente en que anticipa hechos que debemos evitar o minimizar en cuanto a sus consecuencias).

2) Las legislaciones respecto del medio ambiente que no incluyen la categoría de derechos de generaciones futuras, ¿no implican un concepto restringido del concepto de "responsabilidad" o "deber", que en última instancia incluye su contrario, es decir, "irresponsabilidad" u "omisión del deber" respecto de generaciones futuras?

3) La historia nos muestra que hemos adquirido derechos gracias al esfuerzo de generaciones pasadas (por ejemplo, gracias a la Revolución francesa, o gracias a activistas como Martin Luther King). Asimismo hemos perdido derechos o nuestros derechos han sido violentados por obra de generaciones anteriores. Con base en la conciencia de nuestra historicidad, ¿no cabe introducir categorías como "gratitud histórica" o "errores históricos" como criterios de legislación sobre derechos de generaciones futuras? No podemos - como observamos antes - reclamar a las generaciones anteriores, pero bien podemos no incurrir en los mismos errores, así como extender el legado que hemos recibido en la medida en que éste es valioso. 